\title{
Biological Water Quality Assessment of Shallow Urban Streams Based on Abundance and Diversity of Benthic Macroinvertebrate Communities: The Case of Nima Creek in Ghana
}

\author{
L. A. Nuamah ${ }^{1, *}$, J. Huang ${ }^{1}$, H. R. Dankwa ${ }^{2}$ \\ ${ }^{1}$ College of Environmental Science and Engineering, Hohai University, China \\ ${ }^{2}$ CSIR-Water Research Institute, Ghana
}

Copyright $\bigcirc 2018$ by authors, all rights reserved. Authors agree that this article remains permanently open access under the terms of the Creative Commons Attribution License 4.0 International License

\begin{abstract}
The phenomenon of water pollution constitutes a massive threat to the very existence of freshwater bodies and can potentially eliminate vital benefits otherwise associated with these resources. In several countries such as Ghana, initial steps to salvage existing freshwater bodies have given rise to the need for effective water quality assessment and biological monitoring. This study was conducted with the aim of assessing the abundance, composition, and diversity of benthic macroinvertebrate fauna in the Nima Creek, situated in Accra, Ghana. On the basis of findings in relation to identified macroinvertebrate types, we further determine the quality of water in the creek. Samples were collected at 8 different riffles with a Surber sampler. The benthic macroinvertebrates sampled consisted of 6 taxa and 5891 individuals belonging to Nematoda, Oligochaeta, Gastropoda, and Insecta classes. Chironomini were the predominant group with $99.04 \%$ on the average, followed by Psychoda sp $(0.44 \%)$, Rhabitidae $(0.26 \%)$, and Tubifex $(0.26 \%)$ at the upstream stretch of the creek. The downstream was dominated by Chironomini forming $97.30 \%$ on the average, followed by Tubifex $(1.52 \%)$, Rhabitidae (1.08\%), and Psychoda sp (0.05\%). The estimated diversity of the sampling area for both upstream and downstream was assessed by using the Simpson Diversity Index and was found to be 0.53 , indicative of a fairly diversified community structure. Family Biotic Index (FBI) was used to determine the water quality of the creek and found to be 9.92, which indicates severely polluted water. One-way analysis of variance (ANOVA) revealed no significant differences between upstream and downstream abundances at both $95 \%$ and $99 \%$ confidence levels. However, Melanoides tuberculata was found only at the downstream reach due to low current, the formation of rocky substratum, and the absence of riparian

vegetation making it a suitable habitat.

Keywords Benthic Macroinvertebrate, Riffles, Simpson Diversity Index, Family Biotic Index (FBI)

\section{Introduction}

Streams, lakes, and rivers provide a home for the most diverse communities of plants and animals comprising invertebrate forms such as larva insects, annelids (worms), and Mollusca and crustaceans [1, 2]. Freshwater resources in many developing countries, including Ghana, have not been adequately utilized in spite of their abundance. Anthropogenic activities are major culprits owing to their significant contributions to widespread high-levels of pollution in these water resources. Typical amongst these activities are sewage discharge, agricultural runoffs, etc. [3]. One major effect of the disturbance associated with these activities is organic enrichment. This process is of particular importance mainly because of its ability to influence macrobenthic community structure and composition $[4,5]$.

Benthic macroinvertebrates are an essential part of the food web and the interconnection of a food chain. This is partly because of their abundance and position in the aquatic web. They play a critical role in the natural flow of energy and nutrient $[6,7]$. In most streams, the energy available to organisms is stored in plants and made available to animal life in the form of leaves, algae, and bacteria. Macroinvertebrate feed on these leaves, algae, and bacteria, which are at the lower end of the food web. In turn, macroinvertebrates serve as a source of energy (food) for larger animals such as fish, which in turn also act as
\end{abstract}


source of energy (food) for birds and amphibians [8]. In addition, they serve as bioindicators, in that they are used to assess the quality of water. Some stream macroinvertebrates may tolerate high levels of pollution, while others cannot survive or even thrive in polluted water [9-11]. Although water resources with high water quality generally have diverse and rich macroinvertebrate fauna, certain pristine environments have a low diversity of macroinvertebrate fauna because of the cold temperature and/or relatively low nutrient levels. Stonefly larvae (Plecoptera), for example, require high dissolved oxygen concentrations and tend to be found in cold, flowing water with a gravel or stone bottom [12]. Thus, in a polluted stream, there are usually large numbers of a few species, while in a clean stream there are moderate numbers of many species [13]. Since pollution sensitive and tolerant forms are present in "clean" waters, the absence of the former coupled with the presence of the latter provides the basis for the indication of the extent of contamination. The use of a single species or group of species to provide information on the degree of pollution or the overall water quality has a long history in freshwater systems [5].

Studies on benthic macroinvertebrates in response to pollution have been carried out in quite a number of countries including Ghana. Baa-Poku et al. [3] observed that the Nima Creek was indicative of a disturbed urban creek with effluents impacting macroinvertebrate communities. Thorne and Williams [14] also observed that the macroinvertebrate communities in many developing countries in the tropics displayed similar response to pollution relative to that observed in temperate areas. Benbow et al. [15] observed that specific macroinvertebrate taxa may be used as aquatic biological indicators of the pathogen Mycobacterium ulcerans of Buruli ulcer (BU), a tropical disease transmitted by the aquatic macroinvertebrate vector the biting Hemiptera. In addition, the control of causative organisms, such as Simulium and Bulinus, has been one of the main macroinvertebrate studies in Ghana [16]. Related studies carried out include: the annual cycles of macroinvertebrates of the Pawmpawm River in Southern Ghana [17]; the macroinvertebrate fauna of the Ankobra basin [18], and macroinvertebrate communities in the Odaw stream running through Accra [19]. Amuzu [20] and Dartey [21] also assessed the impact of urbanization and microbial populations of the Nima Creek in Accra.

The Nima creek, which is not used for drinking purposes, is of economic importance to the inhabitants living in its catchment area. The creek, which serves as the main source of water for irrigation for vegetable farmers along its banks, also receives effluent discharges from the waste treatment plants of some public buildings. The study, therefore, aimed to firstly, evaluate and assess the water quality of the Nima creek using the occurrence of macroinvertebrates. Secondly, examine the distribution or occurrence of taxa in upstream and downstream macroinvertebrates in the Nima creek. And finally determine the diversity and abundance of macroinvertebrates in the Nima creek.

\section{Materials and Methods}

The study was conducted in the Nima creek located within the Greater Accra region of Ghana. This urban creek stretches from the Kotoka International Airport and discharges into the Odaw River at Kwame Nkrumah Circle (Figure 1). Drains from the nearby environs such as the Opeibea house, Golden Tulip Hotel, and the Council for Scientific and Industrial Research (CSIR) are discharged into the creek. Farmers nearby use the stream for irrigation activities, and run-offs from the farm enter directly into the stream leading to a high level of nutrients in the stream. The Nima creek has a catchment of about $6.7 \mathrm{~km}^{2}$. Its topography is gently rolling except at the headwaters where it is slightly hilly. A large proportion of the basin ranges in elevation from 5.4 to $55.6 \mathrm{~m}$ above sea level [3]. The creek is a fast flowing shallow water body with its bed consisting of large rocks and stones. It is heavily shaded by riparian vegetation, particularly vegetation such as rushes and sedges, which balance the water flow, light availability, and temperature levels of the stream. 


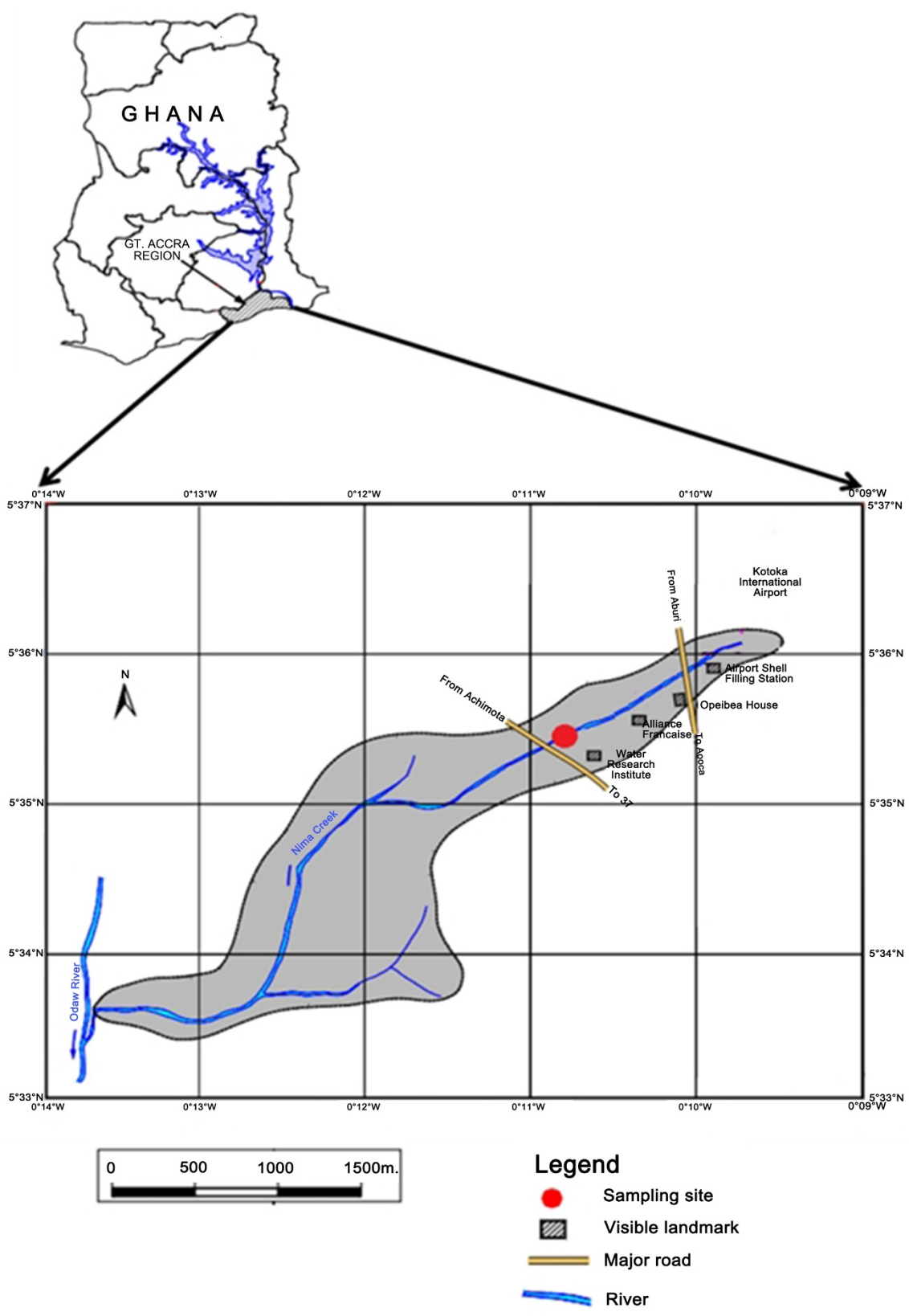

Figure 1. Study Area

The depth of the stream was measured using the meter stick and found to be $0.3 \mathrm{~m}$ deep and $1.12 \mathrm{~m}$ wide. The surber sampler was used to collect the samples. The samples were collected randomly at eight different riffles extending from upstream to downstream. The bridge was used as the midpoint of the stream. The surber sampler was positioned firmly on the floor of the steam facing upstream. Sampling was done by holding the surber firmly against the substrate and then disturbed by stirring the sediments. The net was then rinsed several times in the water body to allow excess sediments stuck in the net to pass through into the container. Each sample was labeled with a white paper which had the following information: the stream name, location, date, and sampler name, and was placed inside the containers. $10 \%$ formalin was used to preserve the macroinvertebrates, which were subsequently taken to the lab to be sorted and identified with the aid of the dissecting microscope. The major taxonomic group of each organism was identified and they were subsequently counted. The percentage composition of macroinvertebrates upstream and downstream was determined using Simpson's Diversity Index (D), which considers not only the number of species (richness) and the total number of individual but also the proportion of the total that occur in each species (evenness). Thus, this index accounts for both species richness and evenness, and was calculated according to the 
equation:

$$
D=1-\sum \frac{n_{i}\left(n_{i}-1\right)}{N(N-1)}
$$

Where $n_{i}$ is the number of individuals in the $i^{t h}$ species, $N$ is the total number of individuals in the sample, and $s$ is the total number of species in the sample.

The Family Biotic Index (FBI), which is based on categorizing macroinvertebrates depending on their response to organic pollution, was used to assess the quality of the creek. Using the Hilsenhoff [22] equation, the FBI was calculated as follows:

$$
F B I=-\sum \frac{x_{i} * t_{i}}{n}
$$

Where $x_{i}$ is the number of individuals in the $i^{\text {th }}$ taxon, $t_{i}$ is the tolerance value of the $i^{t h}$ taxon, and $n$ ' is the total number of organisms in the sample. Variations between the upstream and downstream macroinvertebrate communities were tested using one-way analysis of variance (ANOVA). Prior to the analysis the respective abundance data were log transformed.

\section{Results}

The results for the upstream (Table 1) and downstream (Table 2) sampling were compared with the standards outlined by Hilsenhoff [22].

Table 1. Upstream sampling results

\begin{tabular}{|c|c|c|c|c|c|c|c|}
\hline \multirow{2}{*}{ Species } & \multicolumn{9}{|c|}{ Surber net } & \multirow{2}{*}{ Total } & \multirow{2}{*}{ \% Abundance } \\
\cline { 2 - 8 } & $\mathbf{1}$ & $\mathbf{2}$ & $\mathbf{3}$ & $\mathbf{4}$ & $\mathbf{5}$ & & 98.52 \\
\hline Chironomus formosipennis & 711 & 892 & 701 & 816 & 677 & 3797 & 0.52 \\
\hline Polypedilum abyssinae & 5 & 2 & 3 & 3 & 7 & 20 & 0.44 \\
\hline Psychoda sp & 0 & 0 & 2 & 1 & 14 & 17 & 0.26 \\
\hline Rhabitidae & 2 & 2 & 1 & 0 & 5 & 10 & 0.26 \\
\hline Tubifex & 3 & 3 & 1 & 0 & 3 & 10 & \\
\hline
\end{tabular}

Table 2. Downstream sampling results

\begin{tabular}{|c|c|c|c|c|c|}
\hline \multirow{2}{*}{ Species } & \multicolumn{3}{|c|}{ Surber net } & \multirow{2}{*}{ Total } & \multirow{2}{*}{ \% Abundance } \\
\cline { 2 - 5 } & $\mathbf{1}$ & $\mathbf{2}$ & $\mathbf{3}$ & & 96.81 \\
\hline Chironomus formosipennis & 738 & 595 & 639 & 1972 & 0.05 \\
\hline Melanoides tuberculata & 0 & 0 & 1 & 1 & 0.49 \\
\hline Polypedilum abyssinae & 2 & 4 & 4 & 10 & 0.05 \\
\hline Psychoda sp & 0 & 1 & 0 & 1 & 1.08 \\
\hline Rhabitidae & 2 & 0 & 20 & 22 & 1.52 \\
\hline Tubifex & 3 & 16 & 12 & 31 & \\
\hline
\end{tabular}

Chironomus formosipennis, polypedilum abyssinae, psychoda sp, rhabitidae, and tubifex were present in the upstream. Melanoides tuberculate was not present in the upstream. In the downstream, chironomus formosipennis, polypedilum abyssinae, psychoda sp, rhabitidae, tubifex and melanoides tuberculate were present.

The percentage abundance of macroinvertebrates in upstream and downstream communities are respectively shown in Figure 2 and Figure 3.

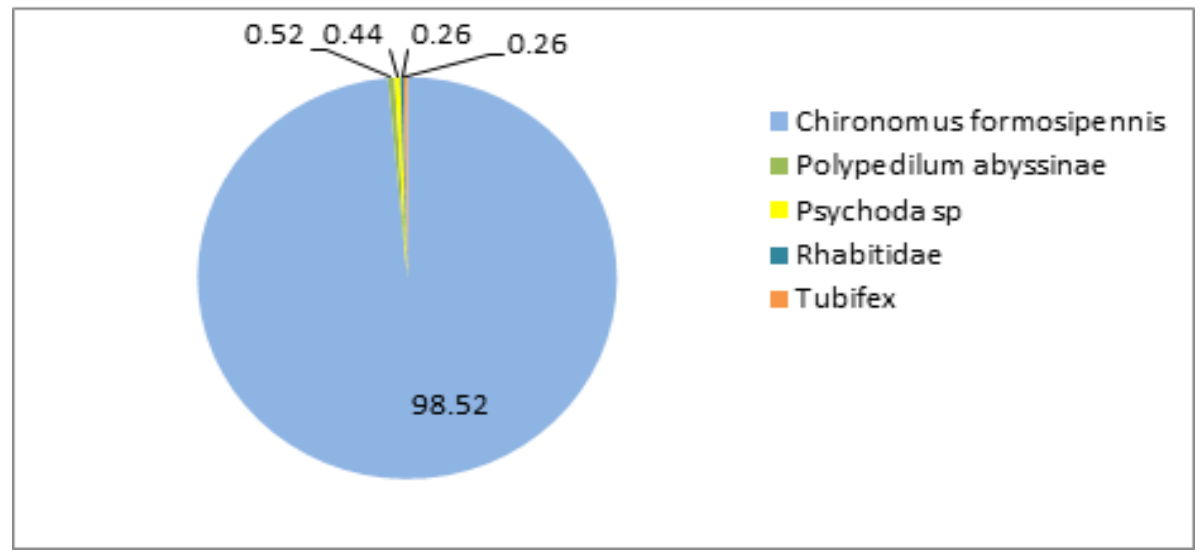

Figure 2. A pie chart showing the percentage abundance of macroinvertebrates in the upstream community 


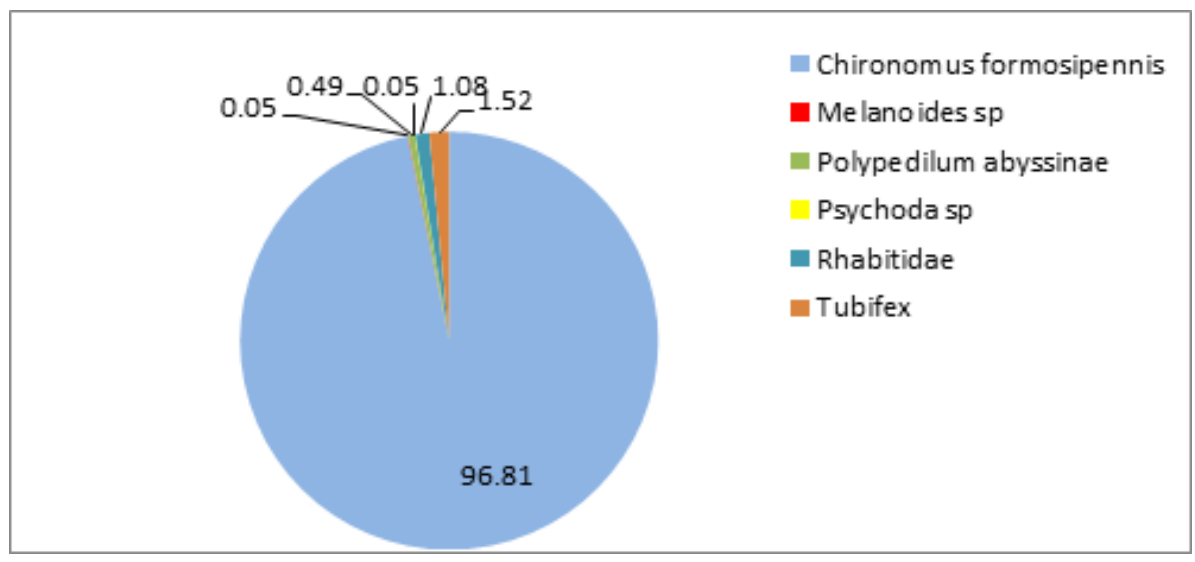

Figure 3. A pie chart showing the percentage abundance of macroinvertebrates in the downstream community

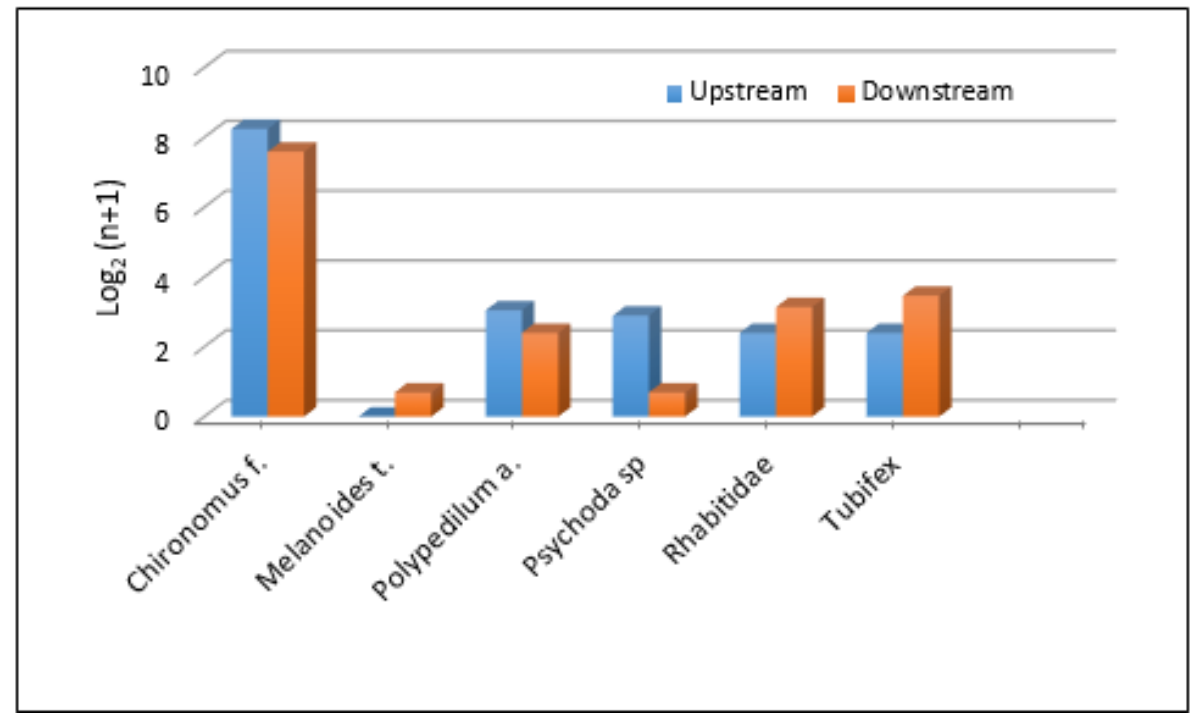

Figure 4. A bar chart comparing the log abundances of individual species found at the two respective reaches.

From Figure 4, both Chironomus formosipennis and polypedilum abyssinae. have higher occurrence upstream than downstream. This observation is also true for Psychoda sp. However, an opposite trend of higher downstream presence can be instead seen for Rhabitidae and Tubifex. Clearly, Figure 4 also shows the occurrence of Melanoides tuberculate solely at the downstream community.

Figure 5 shows the rank abundance curves (RAC) or Whittaker plots of the upstream (top plot) and downstream (bottom plot) communities respectively. The RAC chart is very useful in displaying relative species abundance since it is an effective tool for visualization of species richness and species evenness. Based on the higher number of species on the curve of the downstream community (i.e. 6), it can be inferred that species richness is higher downstream. However, considering the slope of the two curves, macroinvertebrate species evenness can be seen to be slightly higher upstream since the upstream curve is comparatively less steep. Additionally, from both curves the highest ranking species is obviously Chironomus formosipennis. Upstream, tubilflex is the lowest ranked whereas Melanoides tuberculate and psychoda rank least downstream. 


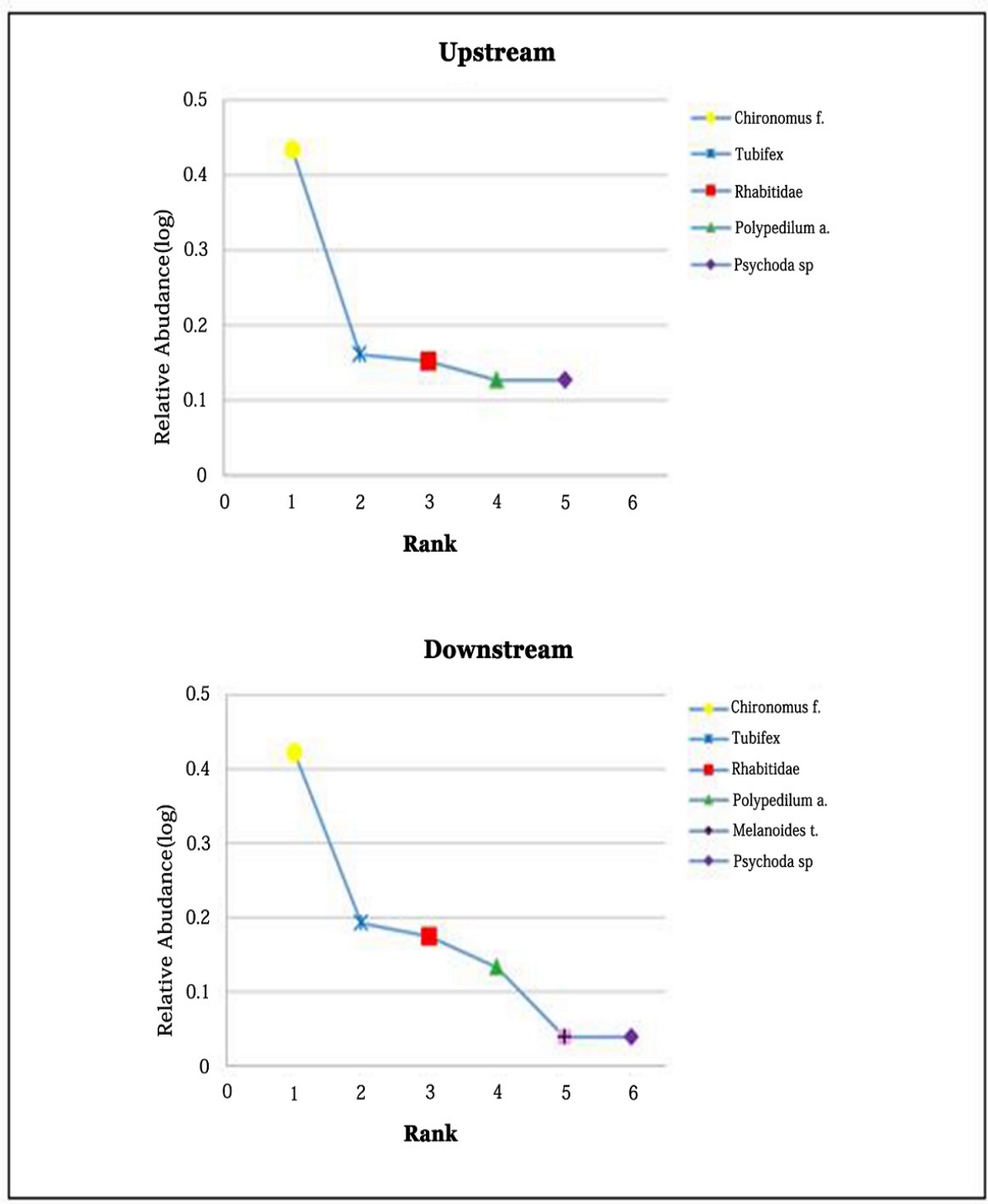

Figure 5. Rank Abundance Curves of the upstream (top) and downstream (down) benthic macroinvertebrate communities.

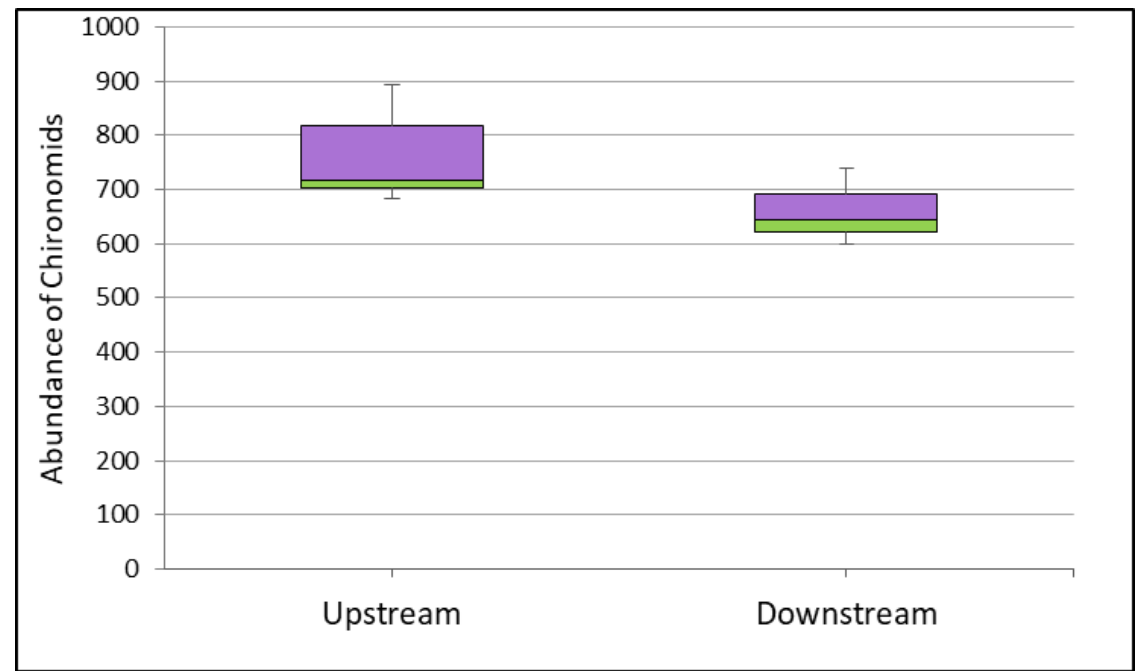

Figure 6. Box-plots of the Chironomid abundance at the two reaches. The middle black line, lower and upper edges and bars of the boxes represent median values, lower and upper quartiles and maximum and minimum values respectively. 
In order to illustrate the dispersion within chironomid dataset and non-chironomid dataset we present their respective abundance $(\ln (n+1))$ per Surber within the two sites as boxplots in Figures 6 and 7. As shown in figure 6, the highest abundances of chironomids were obtained upstream whereas the lowest were obtained downstream. This is confirmed by the higher median of the upstream plot relative to the downstream plot. However, the whiskers of the plots for the two sites intercept thereby indicating lack of significant differences between the sites in terms of the spatial variation of chironomids along the creek. On the other hand, for the non-chironomids (Figure. 7) the distribution of the two data sets appears to be different in a way which is not merely the result of difference in location. The median for the downstream data is close to the upper adjacent value for the upstream non-chironomids, which leads to the conclusion that the non chironomid abundance varies along the stream. The main difference between the two plots lies in their different concentrations around the median rather than their overall spread of values.

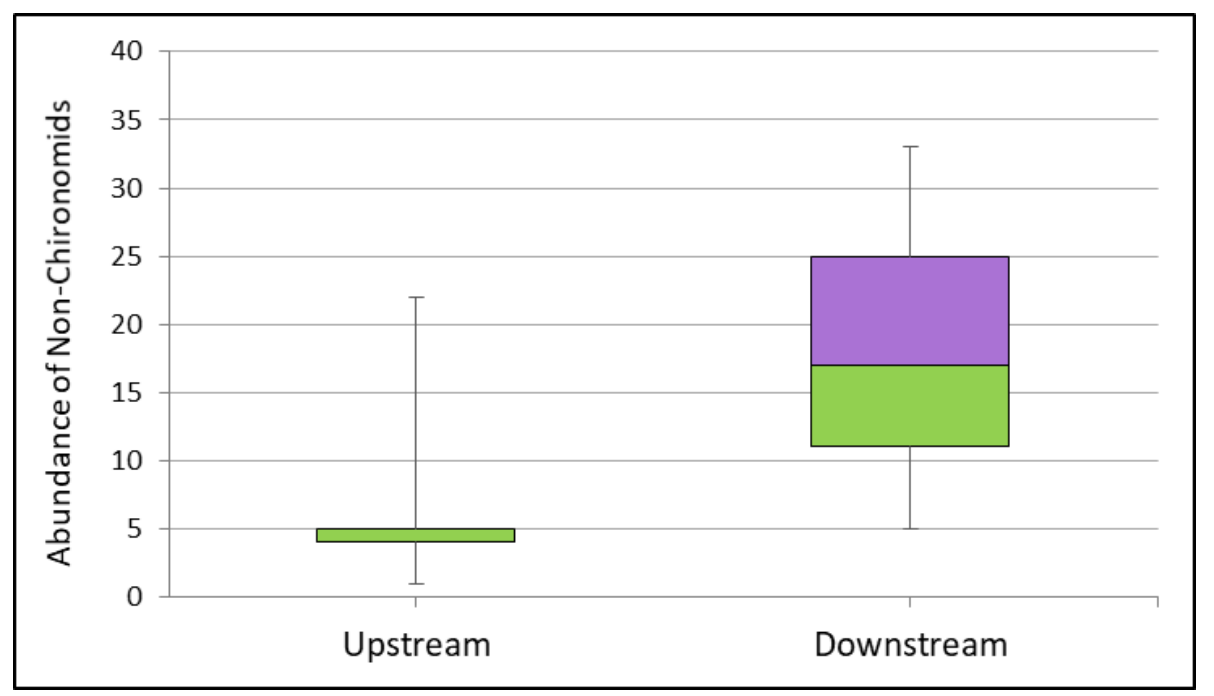

Figure 7. Box-plots of the Non-Chironomid abundance at the two reaches. The middle black line, lower and upper edges and bars of the boxes represent median values, lower and upper quartiles and maximum and minimum values respectively

The results after conducting the one-way ANOVA test on the log transformed (i.e. $\ln (n+1))$ abundance data for the upstream and downstream macroinvertebrate communities are provided in Table 3.

Table 3. Results of the one-way ANOVA test applied to examine variations in abundance at the two reaches

\begin{tabular}{|c|c|c|c|c|c|c|}
\hline Source of Variation & SS & $\boldsymbol{d f}$ & $\boldsymbol{M S}$ & $\boldsymbol{F}$ & $\boldsymbol{P}$-value & F crit (95\%, 99\%) \\
\hline Between Groups & 0.203465 & 1 & 0.203465 & $\mathbf{0 . 0 2 5 7 1 5}$ & $\mathbf{0 . 8 7 4 8 8 9}$ & $4.60011 / 8.861593$ \\
\hline Within Groups & 110.7713 & 14 & 7.912236 & & & \\
\hline Total & 110.9748 & 15 & & & & \\
\hline
\end{tabular}

The result for the calculation of FBI is shown in Table 4.

Table 4. Results of Family Biotic Index

\begin{tabular}{|c|c|c|c|c|c|c|c|c|c|c|c|}
\hline \multirow{2}{*}{ Taxa } & \multicolumn{8}{|c|}{ Suber net } & \multirow{2}{*}{$\mathbf{x}_{\mathbf{i}}$} & \multirow{2}{*}{ Tolerance Value $\left(t_{i}\right)$} & \multirow{2}{*}{$t_{i}^{*} x_{i}$} \\
\hline & 1 & 2 & 3 & 4 & 5 & 6 & 7 & 8 & & & \\
\hline Chironomus formosipennis & 711 & 892 & 701 & 816 & 677 & 738 & 595 & 639 & 5769 & 10 & 57690 \\
\hline Melanoides tuberculata & 0 & 0 & 0 & 0 & 0 & 0 & 0 & 1 & 1 & 0 & 0 \\
\hline Polypedilum abyssinae & 5 & 2 & 3 & 3 & 7 & 2 & 4 & 4 & 30 & 6 & 180 \\
\hline Psychoda sp & 0 & 0 & 2 & 1 & 14 & 0 & 1 & 0 & 18 & 10 & 180 \\
\hline Rhabitidae & 2 & 2 & 1 & 0 & 5 & 2 & 0 & 20 & 32 & 0 & 0 \\
\hline Tubifex & 3 & 3 & 1 & 0 & 3 & 3 & 16 & 12 & 41 & 10 & 410 \\
\hline
\end{tabular}




\section{Discussion/ Conclusions}

A total of 6 macroinvertebrate taxa were found in the Nima creek. These 6 taxa consisted of 3 diptera, 1 mollusca, 1 oligochaeta, and 1 nematoda. The macroinvertebrate benthos indicated by samples examined in the study was significantly similar in the upstream and downstream reaches. A total of five (5) taxa were recorded in the upstream while six (6) were recorded downstream. Both reaches had varying populations of macroinvertebrate benthos. However, the samples presented a similar proportion of the same macroinvertebrate taxa [23], suggesting no significant difference between the upstream and downstream reaches in terms of abundance. This observation is further confirmed when the log transformed data is subjected to one way ANOVA as the results from the analysis indicated that the variation between the two reaches was not statistically significant at both $95 \%$ and $99 \%$ confidence intervals $(\mathrm{F}=0.026, \mathrm{p}=0.87)$. Melanoides tuberculata was present downstream, but absent upstream and this species is noted to be associated with extremely high levels of pollution. Factors that may have aided in making the downstream reach its preferred habitat include low current, the formation of rocky substratum, and the absence of riparian vegetation making it a suitable habitat. The most frequent and highest ranked species is Chironomus formosipennis with a total of 5,769 macroinvertebrates and a percentage abundance of $98.52 \%$ and $96.81 \%$ representing the upstream and downstream reaches respectively. The genus Chironomus is known to be tolerant of organic pollution. On the basis of the results presented above, Chironomid abundance can be seen to be significantly higher at both streams albeit slightly lower downstream. Therefore, the high numbers of Chironomini in the creek confirms the polluted state of the creek [3]. Furthermore, species richness was found to be higher downstream whereas species evenness is slightly higher upstream. Nonetheless, considering the overall macroinvertebrate abundance data at the creek, Simpsons Diversity Index was found to be 0.53 which indicates that the benthic community of the creek is fairly diverse. From Table 4, the Family Biotic Index (FBI) was found to be 9.92, which indicates that the water is of very poor quality and has severe organic pollution. The poor water quality may be attributed to agricultural field runoff that includes nutrients and pesticides. Both may degrade the water quality dramatically but are present for only a few hours after heavy rainfall. Industrial and urban discharge may also severely affect the water quality and also lead to abundance of few species in polluted water and a moderate number of many species in clean water.

Reduced macroinvertebrate fauna at both upstream stations and downstream stations was observed. The run-off probably caused a disturbance in the life cycle and migration of less tolerant benthic macroinvertebrates, resulting in the non-sensitive species increasing in population density due to the decline of competition with the more sensitive species. It is apparent from the study that the quality of the creek's water deteriorated as one moves downstream, and this was mainly due to the untreated organic waste discharges. This has resulted in the loss of species diversity, a situation that may have adverse effects on the proper functioning of the creek's ecosystem. The impact of effluents on the Nima creek must be monitored to avoid further extinction of sensitive species, which are already declining in population, as this study has pointed out.

Based on the research findings it is recommended that an effective regular assessment and monitoring of effluents from waste treatment plants before discharging into freshwater bodies by the appropriate regulatory agencies and institutions must be conducted; enforcement of Environmental Impact Assessment laws by the Environmental Protection Agency of Ghana on all new developmental projects along the catchment area of the creek, including those that were ongoing at the time of this study; and education of members of the communities along the creek on the negative impact of their activities on the creek and its effect on the benthos of our freshwaters. Further studies should be extended to cover other parts of the creek in order to fully document changes in water quality and community structure, and the extent and duration of such changes in order to understand the process of pollution in this creek.

\section{Acknowledgements}

This work was supported by the Hydrobiology Division of the Council for Scientific and Industrial Research Institute (CSIR). Special thanks go to Dr. J.A Quaye-Ballard of Kwame Nkrumah University of Science and Technology (KNUST) for logistics support; Mr. G. Amegbe of the CSIR for his assistance during the field and Laboratory work; and The College of Environmental Science of Hohai University for office and Lab space.

\section{REFERENCES}

[1] Johnson BR, Stribling JB, Paul JEFMJ. 0 Benthic Macroinvertebrates 1999.

[2] EPA US. Water Facts 2004:3-4.

[3] Asante F, Amakye JS. Impact of Urban Effluents on the Macroinvertebrates of 97 a Creek in Accra, Ghana 1998:97109.

[4] Sampaio L, Rodrigues AM, Quintino V. Carbon and nitrogen stable isotopes in coastal benthic populations under multiple organic enrichment sources. Mar Pollut Bull 2010;60:1790-802.

doi:http://dx.doi.org/10.1016/j.marpolbul.2010.06.003. 
[5] Pearson TH, Rosenberg R. Macrobenthic succession in relation to organic enrichment and pollution of the marine environment. Ocean Mar Biol Ann Rev 1978;16:229-311.

[6] Lea R. Aquatic Living Resources 1994;7:165-79.

[7] Gordon C. Biodiversity and Conservation 2000;9(4):46578.

[8] Aggrey-Fynn J, Galyuon I, Aheto DW, Okyere I. Assessment of the environmental conditions and benthic macroinvertebrate communities in two coastal lagoons in Ghana. Ann Biol Res 2011;2.

[9] Nazarova LB, Semenov VF, Sabirov RM, Efimov IY. The state of benthic communities and water quality evaluation in the Cheboksary Reservoir. Water Resour 2004;31:316-22.

[10] Acharyya S, Mitsch WJ. Macroinvertebrate diversity and its ecological implications in two created wetland ecosystems 2001.

[11] Mekong River Commission VP. Biomonitoring Methods for the Lower Mekong Basin. MRC, Vientiane,(Lao PDR); 2010 .

[12] Peckarsky BL, Horn SC, Statzner B. Stonefly predation along a hydraulic gradient: a field test of the harsh-benign hypothesis. Freshw Biol 1990;24:181-91.

[13] Zimmerman MC. The use of the biotic index as an indication of water quality. Test Stud Lab Teach 1993;5:85-98.

[14] Thorne R, Williams P. The response of benthic macroinvertebrates to pollution in developing countries: a multimetric system of bioassessment. Freshw Biol
$1997 ; 37: 671-86$.

[15] Benbow ME, Kimbirauskas R, McIntosh MD, Williamson H, Quaye C, Boakye D, et al. Aquatic Macroinvertebrate Assemblages of Ghana, West Africa: Understanding the Ecology of a Neglected Tropical Disease. Ecohealth 2014;11:168-83.

[16] Hynes JD. Downstream drift of invertebrates in a river in southern Ghana. Freshw Biol 1975;5:515-32.

[17] Hynes JD. Annual cycles of macro - invertebrates of a river in southern Ghana. Freshw Biol 1975;5:71-83.

[18] Osafo RA, Paintsil DA. Pollution and water quality studies: Effect of mining activities on River Ankobra and its tributaries. Hase II, WRRI, Accra 1994.

[19] Thorne RSJ, Williams WP, Gordon C. The macroinvertebrates of a polluted stream in Ghana. J Freshw Ecol 2000;15:209-17.

[20] Amuzu A. T. N-AE and B-HEK. Impact of Development and Urbanization on Urban River Water Quality - The Nima Creek Example. 1995.

[21] Dartey G. A. Assessment of microbial population of a stream and a hotel effluent(Higher diploma in microbial techniques). 1999.

[22] Hilsenhoff WL. An improved biotic index of organic stream pollution. Gt Lakes Entomol 1987;20:31-40.

[23] Lenz BN, Miller MA. Comparison of aquatic macroinvertebrate samples collected using different field methods. Order 1996;5:4. 